\title{
EXIGÊNCIA DE CÁLCIO PARA CODORNAS JAPONESAS (Coturnix coturnix japonica) MACHOS NA FASE DE 1 A 21 DIAS DE IDADE ${ }^{1}$
}

\author{
Calcium requirement for male japanese quails \\ (Coturnix coturnix japonica) from 1 to 21 days of age ${ }^{1}$
}

Fernando Guilherme Perazzo Costa ${ }^{2}$, Patrícia Araújo Brandão ${ }^{3}$, Janete Gouveia Souza ${ }^{2}$,
José Humberto Vilar da Silva ${ }^{4}$, Cláudia de Castro Goulart ${ }^{5}$, Carlos Bôa-Viagem Rabello

RESUMO

Objetivou-se, com esta pesquisa, determinar a exigência de cálcio de codornas japonesas machos, no período de 1 a 21 dias de idade. Foram utilizadas 280 codornas com peso médio de $8 \pm 2 \mathrm{~g}$ na fase inicial. As variáveis estudadas foram consumo de ração (CR), ganho de peso (GP) e conversão alimentar (CA). O delineamento experimental utilizado foi o inteiramente ao acaso, constituído de sete níveis de cálcio para cada fase, com quatro repetições de dez aves por unidade experimental. Os níveis de cálcio foram 0,$85 ; 1,00 ; 1,15 ; 1,30 ; 1,45 ; 1,60$ e 1,75\%. As suplementações de cálcio foram realizadas através do calcário calcítico da ração. Verificou-se que o CR, o GP e a CA apresentaram efeito quadrático com o aumento dos níveis de cálcio na dieta. Recomenda-se dieta contendo $1,24 \%$ de cálcio para codornas japonesas machos no período de 1 a 21 dias de idade.

Termos para indexação: Calcário calcítico, desempenho, mineral.

\begin{abstract}
The objective of this study was to determine calcium requirement of male japanese quails from 1 to 21 days of age. 280 quails with average weight of $8 \pm 2 \mathrm{~g}$ in the initial phase were used. The evaluated performance parameters were feed intake (CR), weight gain (GP) and feed conversion (CA). A completely randomized experimental design was used, with seven calcium levels and four replicates of ten birds per experimental unit. Calcium levels were $0.85,1.00,1.15,1.30,1.45,1.60$ and $1.75 \%$. Limestone was added to the diet as calcium supplementation source. It was found that CR, GP and CA showed a quadratic effect with the increased levels of calcium in the diet. It is recommended diet containing $1.24 \%$ calcium for male japanese quail in the period from 1 to 21 days of age.
\end{abstract}

Index terms: Limestone, performance, mineral.

(Recebido em 10 de abril de 2007 e aprovado em 19 de março de 2009)

\section{INTRODUÇÃO}

Para viabilizar uma exploração racional de codornas, seja para a produção de ovos, seja para produção de carne, torna-se necessária a realização de pesquisas visando a obtenção de material genético de alta qualidade, produzindo, assim, linhagens comerciais com características de desempenho com exigências nutricionais definidas para a adoção de programas adequados de alimentação, manejo e sanidade (Murakami \& Ariki, 1998).

No que se refere às necessidades de minerais para aves, os macrominerais como cálcio e fósforo aparecem como os mais limitantes.

Desta forma, estes devem estar disponíveis na dieta em quantidades e proporções adequadas para atender às necessidades dos animais, considerando a idade, a raça, a categoria ou a situação fisiológica e o sistema de produção adotado (Gomes et al., 2004).

Ao se analisarem as tabelas do AEC (1987) e National Research Council - NRC (1994), observa-se que não há uniformidade na determinação dos períodos referidos para as fases inicial e de crescimento e nem ao menos nos níveis nutricionais recomendados para as fases inicial e de produção de ovos (Murakami \& Ariki, 1998).

O NRC (1994) mostra as exigências nutricionais de codornas japonesas sem precisar, entretanto, o término do período de crescimento, ao passo que o AEC (1987) divide a fase inicial de criação em dois períodos de 0 a 3 e 4 a 7 semanas e ambas as tabelas referem-se às exigências nutricionais na fase de produção em apenas uma fase para todo o período de postura. No entanto, sabe-se que as exigências nutricionais das codornas são alteradas em

${ }^{1}$ Parte da Tese do segundo autor do Programa de Doutorado Integrado em Zootecnia/CCA/UFPB

${ }^{2}$ Universidade Federal da Paraíba/UFPB - Centro de Ciencias Agrárias/CCA - Departamento de Zootecnia/DZ - Cidade Universitária - Campus II Cx. P. 66 - 58397-000 - Areia, PB - fperazzo@cca.ufpb.br

3Universidade Federal de Campina Grande/UFCG - Centro de Saúde e Tecnologia Rural/CSTR - Patos, PB

${ }^{4}$ Universidade Federal da Paraíba/UFPB - Centro de Formação de Tecnólogos/CFT - Bananeiras, PB

${ }^{5}$ Universidade Estadual Vale do Acaraú/UVA - Sobral, CE

${ }^{6}$ Universidade Federal Rural de Pernambuco/UFRPE - Departamento de Zootecnia/DZ - Recife, PE

Ciênc. agrotec., Lavras, v. 35, n. 2, p. 410-414, mar./abr., 2011 
função da espécie a ser criada (codorna japonesa ou européia), sexo, idade e objetivo da criação: produção de ovos de consumo, produção de ovos para incubação ou para produção de carne (Albino \& Barreto, 2003).

O Instituto Nacional de la Recherché Agronomique INRA (1999) traz exigências para codornas na fase inicial ( 1 a 21 dias), crescimento (22ํ dia até o abate ou início da produção de ovos) e para a fase de postura, sendo que, para a fase inicial, o valor recomendado de cálcio na ração $(0,88 \%)$ é superior ao encontrado no NRC (1994) para a mesma fase $(0,80 \%)$.

Portanto, realizou-se esta pesquisa com o objetivo de determinar as exigências de cálcio para codornas japonesas machos, no período de 1 a 21 dias de idade.

\section{MATERIAL E MÉTODOS}

O experimento foi conduzido no Setor de Avicultura do Centro de Ciências Agrárias, Campus II, Areia/UFPB. Foram utilizadas 280 codornas japonesas machos (Coturnix coturnix japonica) alojadas em gaiolas sobrepostas, de arame galvanizado com $0,33 \times 0,38 \times 0,16 \mathrm{~m}$, distribuídas num delineamento experimental inteiramente ao acaso (DIC), constituído de sete tratamentos (níveis de cálcio na ração) e quatro repetições de dez aves por unidade experimental. $\mathrm{O}$ experimento foi realizado na fase inicial de criação, de 1 a 21 dias e o peso inicial médio das aves foi de $8 \pm 2 \mathrm{~g}$. As aves receberam ração e água à vontade.

As rações experimentais foram formuladas para atender às exigências nutricionais das codornas, exceto para cálcio (Tabela 1) de acordo com as recomendações de Silva \& Ribeiro (2003). Os tratamentos consistiram em uma ração basal contendo $0,85 \%$ de cálcio, suplementada com calcário calcítico em substituição ao material inerte da ração para alcançar as concentrações de 0,$85 ; 1,00 ; 1,15 ; 1,30$; 1,$45 ; 1,60$ e $1,75 \%$ de cálcio.

As variáveis estudadas foram consumo de ração, conversão alimentar e ganho de peso. Os valores de ganho de peso, consumo de ração, conversão alimentar e mortalidade foram calculados semanalmente.

Os dados obtidos foram submetidos à análise de variância e as estimativas de exigência de cálcio foram estabelecidas através de modelos de regressão linear e quadrática, utilizando o programa SAEG, desenvolvido pela Universidade Federal de Viçosa - UFV (2001).

\section{RESULTADOS E DISCUSSÃO}

$\mathrm{Na}$ Tabela 2, são apresentados os resultados de desempenho quanto ao consumo de ração, ganho de peso e conversão alimentar de codornas, no período de 1 a 21 dias de idade.
O consumo diário de ração no período de 1 a 21 dias de idade foi influenciado de forma quadrática $(\mathrm{P}<0,01)$ pelos níveis de cálcio na ração, com exigência estimada em 1,19\% de cálcio $\left(\mathrm{Y}=3,5111+6,2955 \mathrm{x}-2,6402 \mathrm{x}^{2}, \mathrm{R}^{2}=0,79\right)$. Estes resultados concordam com aqueles obtidos por Qian et al. (1997) e Alves et al. (2000) que, avaliando o efeito de níveis crescentes de cálcio na ração, observaram uma redução do consumo e do ganho de peso de frangos de corte à medida que o nível de cálcio da ração aumentava.

Os níveis de cálcio da dieta também influenciaram quadraticamente $(\mathrm{P}<0,01)$ o ganho de peso diário das codornas. A exigência de cálcio estimada para maior ganho através da equação $\mathrm{Y}=0,7613+2,9971 \mathrm{x}-1,2434 \mathrm{x}^{2}$; $\mathrm{R}^{2}=0,86$, foi de $1,21 \%$ na dieta.

Em Rhodimet... (1993), podemos encontrar a recomendação de $1,0 \%$ de cálcio para codornas no período de 0 a 3 semanas de idade, em rações com $2.900 \mathrm{kcal}$ de $\mathrm{EM} / \mathrm{kg}$ e $24,5 \%$ de PB, enquanto no INRA (1999) encontramos a exigência de $0,85 \%, 0,90 \%$ e $0,95 \%$ de cálcio em rações com 2.800, 3.000 e $3.200 \mathrm{kcal}$ de EM/kg e 23,0, 24,6 e 26,3\% de PB, respectivamente e no NRC (1994), a recomendação de $0,80 \%$ de cálcio em rações com 2.900 $\mathrm{kcal}$ de EM/kg. Portanto, a exigência de cálcio encontrada nesta pesquisa foi superior às encontradas nas principais tabelas utilizadas para formulação de rações.

Simco \& Stepherson (1961), trabalhando com pintos de corte não encontraram efeito no crescimento de aves alimentadas com rações contendo entre 0,5 e $1 \%$ de cálcio. No entanto, Gardiner (1971) observou redução na taxa de crescimento em pintos de corte machos alimentados com rações contendo $0,4 \%$ de cálcio. Esse fato pode provavelmente estar relacionado com a ingestão desse nutriente, porque, quando a ingestão de cálcio ocorre abaixo ou acima das necessidades, a homeostase é restabelecida pela ação dos hormônios envolvidos na sua regulação. Schoulten et al. (2002) relatam que a calcitonina atua em feedback negativo ao paratormônio (PTH), inibindo a absorção intestinal e aumentando a eliminação do cálcio pelos rins e estimulando a sedimentação óssea, sendo este fato observado quando se utilizaram níveis acima de 1,45\% de cálcio na dieta.

A conversão alimentar apresentou melhor resultado com $1,23 \%$ de cálcio na dieta $\left(y=3,3884-0,922 x+0,3757 x^{2}\right.$, $\mathrm{R}^{2}=0,98$ ), o que caracteriza bem a interação entre esse nível de cálcio e o estado nutricional do animal. De acordo com Alves et al. (2002), o estado nutricional do animal tem influência na absorção de cálcio quando animais alimentados com dieta deficiente desse mineral aumentam sua taxa de absorção, enquanto altos níveis dietéticos de cálcio levam à redução da absorção. Segundo Dale (1983), a inclusão de altos níveis de cálcio nas rações aumenta a necessidade de fósforo para frangos de corte. O cálcio interfere na absorção do fósforo, 
complexando-o em nível de intestino, tornando-o menos disponível, além de dificultar a absorção do mesmo pela ave. Alguns trabalhos mostram que quando foram utilizados níveis abaixo de 1,15 e acima de $1,45 \%$ de cálcio na dieta, os resultados de desempenho animal foram piores (Schoulten et al., 2003).

Resultados contrários foram obtidos por Silva (2009) trabalhando com codornas de corte na fase inicial não observaram interações entre os níveis de cálcio e fósforo disponível para as variáveis de desempenho, e mostraram que $0,65 \%$ de cálcio foi suficiente para atender à exigência nutricional das aves nesta fase de criação. Esses resultados confirmam os obtidos por Reddy et al. (1980), que, trabalhando com codornas japonesas em crescimento (1 a 21 dias), estimaram exigência de $0,60 \%$ de cálcio.

Tabela 1 - Composição percentual e calculada da dieta basal na fase inicial (1 a 21 dias).

\begin{tabular}{|c|c|}
\hline Ingredientes & $\%$ \\
\hline Milho grão $^{(1)}$ & 56,56 \\
\hline Farelo de soja $^{(1)}$ & 35,94 \\
\hline Glúten de milho & 0,00 \\
\hline Fosfato bicálcico & 1,62 \\
\hline Calcário & 0,82 \\
\hline Óleo de soja & 2,00 \\
\hline L-lisina $\bullet H C L ~ 78,4 \%$ & 0,07 \\
\hline DL-Metionina & 0,03 \\
\hline Cloreto de colina & 0,15 \\
\hline Premix vitamínico ${ }^{(2)}$ & 0,15 \\
\hline Premix mineral $^{(3)}$ & 0,05 \\
\hline Coccidiostático & 0,00 \\
\hline Promotor de crescimento & 0,00 \\
\hline Sal comum & 0,25 \\
\hline $\mathrm{BHT}^{(4)}$ & 0,01 \\
\hline Inerte & 2,35 \\
\hline Total & 100,00 \\
\hline \multicolumn{2}{|l|}{ Composição calculada $^{(3)}$} \\
\hline Energia metabolizável (kcal/kg) & 2.900 \\
\hline Proteína bruta $(\%)$ & 21,3 \\
\hline Cálcio $(\%)$ & 0,85 \\
\hline Fósforo disponível (\%) & 0,41 \\
\hline Lisina total $(\%)$ & 1,19 \\
\hline Metionina+cistina total (\%) & 0,70 \\
\hline Metionina total (\%) & 0,36 \\
\hline Treonina total $(\%)$ & 0,82 \\
\hline Sódio $(\%)$ & 0,14 \\
\hline
\end{tabular}

${ }^{(1)}$ Valores calculados de acordo com a tabela de Silva \& Ribeiro (2003).

${ }^{(2)}$ Premix vitamínico por kg de ração: Vit. A - 15.000.000 Ul, Vit. $D_{3}-1.500 .000$ Ul, Vit. E - 15.000 Ul, Vit.B $-2,0$ g, Vit.B $-4,0$ g, VitB6 - 3,0 g, Vit.B ${ }_{12}$ - 0,015 g, Ácido nicotínico - $25 \mathrm{~g}$, Ácido pantotênico - $10 \mathrm{~g}$, Vit. $\mathrm{K}_{3}$ - 3,0 g, Ácido fólico - 1,0 g, acitracina de zinco - $10 \mathrm{~g}$, Selênio - $250 \mathrm{mg}$, Antioxidante BHT - $10 \mathrm{~g}$, e veículo q.s.p. - $1.000 \mathrm{~g}$.

${ }^{(3)}$ Premix mineral por kg de ração: $\mathrm{Mn}, 60$ g; Fe, 80 g; Zn, 50 g; Cu, 10 g; Co, 2 g; I, 1 g; e veículo q.s.p., 500 g.

${ }^{(4)}$ Antioxidante (Butil-hidroxi-tolueno-BHT) - $10 \mathrm{~g}$, e veículo q.s.p. - $1.000 \mathrm{~g}$. 
Tabela 2 - Médias do consumo de ração (CR), ganho de peso (GP) e conversão alimentar (CA) de acordo com os níveis de cálcio na ração de codornas machos na fase inicial de criação.

\begin{tabular}{|c|c|c|c|}
\hline $\begin{array}{c}\text { Níveis de Cálcio } \\
(\%)\end{array}$ & $\begin{array}{l}\text { Consumo de Ração } \\
\text { (g/ave/dia) }\end{array}$ & Ganho de Peso (g/ave/dia) & Conversão Alimentar (g/g) \\
\hline 0,85 & 6,99 & 2,42 & 2,88 \\
\hline 1,00 & 7,12 & 2,50 & 2,84 \\
\hline 1,15 & 7,21 & 2,55 & 2,82 \\
\hline 1,30 & 7,23 & 2,56 & 2,82 \\
\hline 1,45 & 7,33 & 2,57 & 2,85 \\
\hline 1,60 & 6,57 & 2,28 & 2,88 \\
\hline 1,75 & 6,52 & 2,23 & 2,92 \\
\hline Média & 7,00 & 2,45 & 2,86 \\
\hline Exigência Estimada (\%) & 1,19 & 1,21 & 1,23 \\
\hline Regressão & $\mathrm{Q}^{* *}$ & $\mathrm{Q}^{* *}$ & $\mathrm{Q}^{* *}$ \\
\hline $\mathrm{CV}(\%)$ & 4,30 & 4,28 & 1,47 \\
\hline
\end{tabular}

$\mathrm{Q}^{* *}=$ Efeito quadrático $(\mathrm{P}<0,01)$.

$\mathrm{CV}=$ Coeficiente de variação.

Shafey \& McDonald (1991) citam diversos trabalhos de pesquisa em que demonstraram depressão do ganho de peso e redução da eficiência alimentar em frangos de corte que receberam ração contendo níveis de cálcio variando de 1,3 a 1,7\%. Contudo, Costa (2009) trabalhando com codornas aos 21 dias de idade verificaram efeito quadrático dos níveis de $\mathrm{Ca}$ da dieta sobre o consumo de ração, o ganho de peso e a conversão alimentar na fase inicial, bem como sobre o teor de Ca na tíbia e no fêmur das codornas obtido com $1,29 \%$ de cálcio.

\section{CONCLUSÕES}

Recomenda-se para codornas japonesas machos dieta contendo 1,24\% de cálcio para a fase inicial, de 1 a 21 dias de idade, quando formulada com $0,41 \%$ de fósforo disponível.

\section{REFERÊNCIAS BIBLIOGRÁFICAS}

AEC. Poulenc animal nutrition: tables AEC. Paris, 1987. 86p.

ALBINO, L.F.T.; BARRETO, S.L.T. Criação de codornas para produção de ovos e carne. Viçosa, MG: Aprenda Fácil, 2003.268p.

ALVES, E.L.; TEIXEIRA, A.S.; BERTECHINI, A.G.; RODRIGUES, P.B.; OLIVEIRA, A.I.G. Efeito dos níveis de cálcio em duas fontes sobre o desempenho de frangos de corte. Ciência Agrotecnologia, Lavras, v.26, n.6, p.1305-1312, nov./dez. 2002.

ALVES, E.L.; TEIXEIRA, A.S.; SANTOS, E.C.; TORRES, D.M.; MUNIZ, E.B. Efeito dos níveis de cálcio em duas fontes sobre o desempenho de frangos de corte de 0 a 4 semanas de idade, criados em cama. Ciência e Agrotecnologia, Lavras, p.905920, 2000.

COSTA, F.G.P.; BRANDÃO, P.A.; SILVA, J.H.V. Exigências de cálcio para codornas japonesas fêmeas de um a 35 dias de idade. Acta Scientiarum Animal

Sciences, Maringá, v.31, n.1, p.7-12, 2009.

DALE, N. Necessidades de fósforos para pollos.

Avicultura Professional, v.1, n.1, p.80-83, 1983.

GARDINER, E.E. Calcium requirements of breeds of chickens as influenced by levels of dietary phosphorus. Canadian Journal of Animal Science, Quebec, v.51, p.445-450, 1971.

GOMES, P.C.; RUNHO, R.C.; ROSTAGNO, H.S. Exigência de fósforo disponível para frangos de corte machos e fêmeas de 22 a 42 e de 43 a 53 dias de Idade. Revista Brasileira de Zootecnia, Viçosa, v.33, n.6, p.1734-1746, 2004. Suplemento 1. 
INSTITUTO NACIONAL DE LA RECHERCHÉ AGRONOMIQUE. Alimentação dos animais monogástricos: suínos, coelhos e aves. 2.ed. São Paulo: Roca, 1999. 245p.

MURAKAMI, A.E.; ARIKI, J. Produção de codornas japonesas. Jabotical: Funep-Unesp, 1998. 79p.

\section{NATIONAL RESEARCH COUNCIL. Nutrient} requirements of poultry. 9.ed. Washington, 1994. 155p.

QIAN, H.; KORNEGAY, E.T.; DENBOW, D.M. Utilization of phytate phosphorus and calcium as influenced by microbial phytase, cholecalciferol, and the calcium: total phosphorus ratio in broiler diets. Poultry Science, Champaign, v.76, n.5, p.37-46, 1997.

REEDY, V.R.; SHRIVASTAV, A.K.; SADAGOPAN, V.R. Calcium and phosphorus requirements growing Japanese quail. British Poultry Science, Cambridge, v.21, p.385-387, 1980.

RHODIMET feed formulation guide. 6.ed. Paris: RhônePoulenc Animal Nutrition, 1993. 39p.

SCHOULTEN, N.A.; TEIXEIRA, A.S.; SILVA, H.O. Efeito dos níveis de cálcio da ração suplementada com fitase sobre a absorção de minerais em frangos de corte de 22 a 42 dias. Revista Ciência Animal Brasileira, Belo Horizonte, v.3, n.1, p.31-37, 2002.
SCHOULTEN, N.A.; TEIXEIRA, A.S.; CONTE, A.J.; SILVA, H.O.; BERTECHINI, A.G.; FIALHO, E.T. Efeito dos níveis de cálcio da ração suplementada com fitase sobre a absorção de minerais em frangos de corte de 22 a 42 dias. Ciência e Agrotecnologia, Lavras, v.27, n.1, p.206-210, 2003.

SHAFEY, T.M.; MCDONALD, M.W. The effects of dietary concentrations of minerals, source of protein, amino acids and antibiotics on the growth and digestibility of amino acids by broiler chickens. British Poultry Science, Edinburgh, v.32, n.3, p.535-544, July 1991.

SILVA, J.H.V.; RIBEIRO, M.L.G. Tabela nacional de exigência nutricional de codornas. Bananeiras: CFT/ DA, 2003.

SILVA, R.M.; FURLAN, A.C.; TON, A.P.S. Exigências nutricionais de cálcio e fósforo de codornas de corte em crescimento. Revista Brasileira de Zootecnia, Viçosa, v.38, n.8, p.1509-1517, 2009.

SIMCO, T.F.; STEPHERSON, E.L. Re-aluation of the calcium-phosphorus requirements of the chick. Poultry Science, Champaign, v.40, p.1188-1192, 1961.

UNIVERSIDADE FEDERAL DE VIÇOSA. Central de Processamento de Dados. Sistema de análise estatística e genética. Viçosa, MG, 2001. 52p. 